\title{
Alpha blockers for treatment of ureteric stones: systematic review and meta-analysis
}

\author{
John M Hollingsworth, ${ }^{1}$ Benjamin K Canales, ${ }^{2}$ Mary A M Rogers, ${ }^{3}$ Shyam Sukumar,, ${ }^{4}$ Phyllis Yan, ${ }^{1}$ \\ Gretchen M Kuntz, ${ }^{5}$ Philipp Dahm ${ }^{4}$
}

1Department of Urology, University of Michigan, 2800

Plymouth Rd, Building 16, 1st

Floor, Ann Arbor, MI 48109, USA

2Department of Urology,

University of Florida, 1600 SW

Archer Rd, Gainesville, FL

32610, USA

${ }^{3}$ Department of Internal

Medicine, Division of General

Medicine, University of

Michigan, 2800 Plymouth Rd,

Building 16, 4th Floor, Ann

Arbor, MI 48109, USA

4Minneapolis Veterans

Administration Health Care

System and Department of

Urology, University of

Minnesota, Mayo Memorial

Building, 420 Delaware St SE

MMC 394, Minneapolis, MN

55455, USA

${ }^{5}$ Borland Library, University of

Florida, 653-1 W 8th St,

Jacksonville, FL 32209, USA

Correspondence to:

J M Hollingsworth

kinks@med.umich.edu

Additional material is published online only. To view please visit

the journal online.

Cite this as: $B M J$ 2016;355:i6112 http://dx.doi.org/10.1136/bmj.i6112

Accepted: 02 November 2016

\section{ABSTRACT}

OBJECTIVE

To investigate the efficacy and safety of alpha blockers in the treatment of patients with ureteric stones.

DESIGN

Systematic review and meta-analysis.

\section{DATA SOURCES}

Cochrane Central Register of Controlled Trials, Web of Science, Embase, LILACS, and Medline databases and scientific meeting abstracts to July 2016.

\section{REVIEW METHODS}

Randomized controlled trials of alpha blockers compared with placebo or control for treatment of ureteric stones were eligible. Two team members independently extracted data from each included study. The primary outcome was the proportion of patients who passed their stone. Secondary outcomes were the time to passage; the number of pain episodes; and the proportions of patients who underwent surgery, required admission to hospital, and experienced an adverse event. Pooled risk ratios and $95 \%$ confidence intervals were calculated for the primary outcome with profile likelihood random effects models. Cochrane Collaboration's tool for assessing risk of bias and the GRADE approach were used to evaluate the quality of evidence and summarize conclusions.

\section{RESULTS}

55 randomized controlled trials were included. There was moderate quality evidence that alpha blockers facilitate passage of ureteric stones (risk ratio 1.49, $95 \%$ confidence interval 1.39 to 1.61 ). Based on a priori subgroup analysis, there seemed to be no benefit to treatment with alpha blocker among patients with smaller ureteric stones $(1.19,1.00$ to 1.48$)$. Patients with larger stones treated with an alpha blocker,

\section{WHAT IS ALREADY KNOWN ON THIS TOPIC}

Several small randomized controlled trials have suggested a role of alpha blockers in promoting passage of ureteric stones

Consequently, contemporary practice guidelines recommend their use as medical expulsive therapy

A recent large methodologically rigorous trial has raised questions about the efficacy of this treatment

\section{WHAT THIS STUDY ADDS}

Medical expulsive therapy is beneficial for multiple health outcomes such as passage of ureteric stone and need for surgical interventions; adverse effects associated with alpha blocker use were relatively infrequent and not severe Medical expulsive therapy with alpha blockers seems of particular benefit in patients with larger ureteric stones however, had a $57 \%$ higher risk of stone passage compared with controls $(1.57,1.17$ to 2.27$)$. The effect of alpha blockers was independent of stone location (1.48 (1.05 to 2.10) for upper or middle stones; 1.49 (1.38 to 1.63) for lower stones). Compared with controls, patients who received alpha blockers had significantly shorter times to stone passage (mean difference -3.79 days, -4.45 to -3.14 ; moderate quality evidence), fewer episodes of pain $(-0.74$ episodes, -1.28 to -0.21 ; low quality evidence), lower risks of surgical intervention (risk ratio $0.44,0.37$ to 0.52; moderate quality evidence), and lower risks of admission to hospital $(0.37,0.22$ to 0.64 ; moderate quality evidence). The risk of a serious adverse event was similar between treatment and control groups (1.49, 0.24 to 9.35 ; low quality evidence).

\section{CONCLUSIONS}

Alpha blockers seem efficacious in the treatment of patients with ureteric stones who are amenable to conservative management. The greatest benefit might be among those with larger stones. These results support current guideline recommendations advocating a role for alpha blockers in patients with ureteric stones.

\section{SYSTEMATIC REVIEW REGISTRATION}

PROSPERO registration No CRD42015024169.

\section{Introduction}

Contemporary practice guidelines from leading professional societies recognize the off-label use of alpha adrenergic antagonists (or alpha blockers) as an initial treatment option for patients with newly diagnosed, uncomplicated ureteric stones $<10 \mathrm{~mm}$ in size, whose symptoms are controlled. ${ }^{12}$ This endorsement is based on several systematic reviews and meta-analyses of numerous randomized controlled trials, which, in aggregate, showed a higher risk of stone passage among patients treated with alpha blockers (their use has been termed medical expulsive therapy) compared with controls. ${ }^{3-9}$ Consequently, such treatment has become part of the routine management algorithm for ureteric colic.

Even ardent proponents of medical expulsive therapy concede that many supporting data come from small, single centre, low quality studies, and a large confirmatory trial has been recommended. This prompted a recent multicentre randomized controlled trial in the United Kingdom that involved over 1100 patients with ureteric stones. ${ }^{10}$ The trail showed this treatment to be no more efficacious than placebo at decreasing four week rates of intervention for stone clearance. In light of these results, the investigators concluded that medical expulsive therapy "should not 
be offered to patients with ureteric colic managed expectantly, giving providers of health care an opportunity to reallocate resources elsewhere.”

Despite the rigor of this trial, concerns have been raised about the choice of primary endpoint and the possibility that other important data might have been overlooked (for example, the high background rate of spontaneous stone passage). ${ }^{11-14}$ Further, while intervention rates were similar between the treatment and placebo groups for smaller and upper/middle ureteric stones, results were consistent with a clinically important effect only in patients with larger, lower calculi. ${ }^{10}$ To help reconcile these issues, we conducted a systematic review, identifying all randomized controlled trials examining alpha blockers for treatment of ureteric stones. We then pooled data to derive estimates of the effect of alpha blockers on stone passage, including a priori subgroup analyses to assess the impact that stone size and location have on efficacy.

\section{Methods}

Data sources and searches

Following the PRISMA (Preferred Reporting Items for Systematic Reviews and Meta-Analyses) statement, ${ }^{15}$ we prospectively registered our review on PROSPERO (CRD42015024169). We established inclusion criteria before beginning our search. We considered all randomized controlled trials in any language that looked at alpha blockers compared with placebo or control for treatment of ureteric stones. Controls were defined a priori as patients who had not received any additional treatment to facilitate stone passage (such as antispasmolytics, antimuscarinics) with the exception of corticosteroids and only if they were applied equally to both treatment arms. We included only those trials in which alpha blockers were used as the main treatment. Thus, we excluded trials in which alpha blockers were examined as an adjuvant to surgery (for example, after shockwave lithotripsy or ureteroscopy).

A Cochrane Collaboration systematic review identified all randomized controlled trials on alpha blockers for ureteric stones published up to 9 July $2012 .^{6}$ This review served as the foundation for our search. One member of our study team, a trained medical librarian, performed an updated electronic search of the Cochrane Central Register of Controlled Trials (via Wiley), Web of Science, Embase, LILACS, and Medline (via PubMed) databases up to 10 July 2016. We used boolean logic to incorporate various terms and synonyms for concepts in each of three distinct filters: an anatomic filter for ureteric stones, a treatment filter for alpha blockers, and a publication type filter for randomized controlled trials. When possible, we used controlled vocabulary (such as MeSH in PubMed, EMTREE in Embase) and key words. Although we tailored the precise strategy to accommodate each database's features, as an example appendix 1 shows the strategy we used in PubMed. Other search strategies are available on request.

In addition, we scanned the reference lists of other published narrative and systematic reviews to identify potential additional studies not retrieved by our electronic search. In an effort to find unpublished studies, we also hand searched abstracts from the annual meetings of the World Congress of Endourology and SWL, the European Association of Urology, and the American Urological Association to 10 July 2016. To identify ongoing trials, we used the WHO International Clinical Trials Registry Platform (ICTRP) and ClinicalTrials.gov search portals.

\section{Study selection}

We used the reference manager software Endnote to identify and remove duplicate records. Next, we imported references into Covidence (www.covidence.org), and two study team members independently scanned each title and abstract. For studies that advanced beyond this stage, two study team members then performed independent full text reviews. We mapped publications relating to the same trial to unique studies. When we found multiple publications from a research group, we contacted the corresponding author to determine whether their reports were from the same study population, and we removed duplicates. We had non-English language articles translated before review. Once we identified all potentially relevant articles, two study team members met to achieve consensus. When necessary, we used third party adjudication to settle disputes.

\section{Data extraction and risk of bias assessment}

For each study selected for inclusion, two team members independently extracted data using a pilot tested standardized form. We resolved inconsistencies between the two through discussion, with a third team member serving as the arbitrator. We collected information on study characteristics (study year, country of origin, publication type, use of placebo, maximum length of follow-up, and imaging use), patients' characteristics (age, sex, and stone size and location), and data on outcomes. Our primary outcome was the proportion of patients who passed their stone. Our secondary outcomes were the time to passage, the number of episodes of pain, and the proportions of patients who underwent surgical intervention, required admission to hospital, and experienced a serious adverse event (as defined by the study authors). We also examined specific adverse events including dizziness, headache, fatigue, malaise, insomnia, hypotension, palpitations, collapse, retrograde/abnormal ejaculation, sexual dysfunction, dyspepsia, diarrhea, nausea, vomiting, constipation, flatulence, abdominal pain, nasal congestion, cough, arthralgia, and rash.

To assess the risk of bias of the selected studies, we used the Cochrane Collaboration's tool on an outcome specific basis. ${ }^{16}$ Relying only on the information presented in the study report and making no assumptions, two team members evaluated each trial across four domains. These domains included sequence generation/allocation concealment (selection bias), blinding of participants and personnel (performance bias), blinding of outcome assessors (detection bias), and completeness of follow-up (attrition bias). For each domain, individual team members judged whether the risk of bias in a given study was "low," "high,” or "unclear.” Any disagreements were referred to a third team member. 


\section{Data synthesis and primary analysis}

We conducted two tailed statistical tests and set the probability of type I error at 0.05 . We performed all calculations using Stata/MP, version 14.1 (StataCorp, College Station, TX). In preliminary analyses, we pooled the proportion of patients who passed stones in each study group (treatment, control) using the random effects profile likelihood method and the Freeman-Tukey double arcsine transformation to stabilize the variance. ${ }^{17}$ Our main estimates of effect were pooled risk ratios with 95\% confidence intervals. Specifically, we compared the proportion of people taking an alpha blocker who passed their stones (numerator) with the proportion not taking an alpha blocker (controls) who passed their stones (denominator). For these comparisons, we fitted random effects models and calculated 95\% confidence intervals using two different estimators-the profile likelihood and restricted maximum likelihood methods. ${ }^{18}$

When the number of pooled studies was small (fewer than 10), we used the more conservative Hartung-Knapp-Sidik-Jonkman method to calculate confidence intervals, ${ }^{19-21}$ which is based on a $t$ distribution. For studies that involved different alpha blockers (for example, tamsulosin and terazosin) or different doses of the same drug (for example, tamsulosin $0.2 \mathrm{mg}$ and $0.4 \mathrm{mg}$ ), we collapsed the separate treatment arms into one for our main analysis. We computed pooled risk differences to generate number needed to treat (calculated as the inverse of the pooled risk difference) with $95 \%$ confidence intervals from the profile likelihood method. To determine whether an early extreme result for treatment with an alpha blocker deviated from the results of later studies (the Proteus phenomenon), we used the approach described by Ioannidis and Trikalinos. ${ }^{22}$ The prediction interval was calculated for the primary outcome (stone passage); this interval reflects the expected future benefits of treatment to patients. ${ }^{23}$

Based on a priori decisions, we also performed subgroup analyses, stratifying by stone size and location. In some trials, the investigators reported outcomes in patients who had smaller versus larger ureteric stones; we used these size thresholds, ranging from $5 \mathrm{~mm}$ to 8 $\mathrm{mm}$, to stratify the results. For our analyses of stone location, we collapsed upper and middle ureteric stones into one category.

To assess statistical heterogeneity, we calculated $\tau^{2}$, which represents variance between studies ( $\tau$ is the estimated standard deviation of the effects across studies). ${ }^{24}$ We also calculated the $\mathrm{I}^{2}$ statistic, which estimates the proportion of variability in the meta-analysis caused by differences between studies rather than sampling error. ${ }^{25}$ Prior empirical work suggests that $\tau^{2}$ performs better than $\mathrm{I}^{2}$ as precision increases. ${ }^{26}$

\section{Sensitivity analyses}

To better understand the sources of statistical heterogeneity between studies, as well as test the robustness of our findings, we then performed a series of sensitivity analyses.

First, we repeated our analysis, excluding those studies in which corticosteroids were co-administered. Second, we restricted our analysis to only those studies published as full length, peer reviewed research articles. Third, we pooled data only from those studies that had placebo controls. Fourth, to evaluate the impact that baseline risk had on our estimates, we conducted meta-regression using the restricted maximum likelihood method for variance between studies with the Knapp-Hartung modification to calculate $P$ values and confidence intervals. We also used meta-regression to assess differences in effect related to length of follow-up and sex composition. Fifth, we performed sensitivity analyses based on variation between studies in the risk of bias. For each of the four domains described above, a study was awarded a point if the risk of bias was judged low. As such, a study could be awarded a maximum of four points. We categorized each study by its point totals as being of low (three or four points), moderate (two points), or high risk of bias (zero or one point). Finally, to examine the effect of individual studies on our summary estimates, we conducted an influence analysis, in which we recalculated pooled estimates omitting one study at a time.

\section{Secondary analyses}

In addition to our primary analysis, we derived summary estimates of effect for our secondary outcomes. When we used continuous scales of measurement (time to stone passage, number of pain episodes), we summarized our findings with the pooled mean difference. For dichotomous outcomes (need for surgical intervention, subsequent admission to hospital, occurrence of an adverse event), we again used pooled risk ratios.

\section{Assessing for publication bias}

We explored the possibility of publication bias visually, checking for asymmetry in contoured funnel plots of treatment effect against its standard error, and with formal statistical procedures. Specifically, we used Harbord's test for dichotomous endpoints and Egger's test for continuous endpoints to examine possible small study effects. ${ }^{27}$

\section{Patient involvement}

No patients were involved in setting the research question or the outcome measures, nor were they involved in developing plans for design or implementation of our study. We did not ask patients for advice on interpretation or writing up of our results. We have no plans to disseminate our results to patient participants from the pooled studies.

\section{Rating quality of evidence for each pooled analysis}

Finally, we rated our confidence in the estimates of effect for each outcome according to the GRADE approach, taking into account study limitations (risk of bias), inconsistency, imprecision, indirectness and publication bias. ${ }^{28}$ For each comparison, two team members independently rated the quality of evidence for each outcome as "high," "moderate," "low," or "very low” using GRADEpro GDT (http://gradepro.org). We resolved discrepancies by consensus, and if needed, with arbitration by a third team member. 


\section{Results}

\section{Search strategy results}

From our electronic search, we identified 286 studies. We found an additional 20 records by hand searching meeting abstracts and from reference lists of other review articles. When we combined these with the 29 references from the 2014 Cochrane review, ${ }^{6}$ there were 443 potentially relevant studies in total. Of these, we excluded 355 during the initial screening phase based on the title and abstract. For the remaining 88 studies, we performed a full text screening and eliminated 33 studies because they included duplicate populations, had an observational design, or their treatment groups received additional treatment to facilitate stone passage. This yielded 55 unique studies (involving 5990 randomized patients) that examined the effect of alpha blockers on ureteric stones (fig 1) and met our inclusion criteria. ${ }^{1029-82}$

\section{Descriptive statistics}

Table A in appendix 2 shows all the studies included in our systematic review, most of which were conducted in Europe and Asia. Thirty nine studies reported mean age in treatment and control groups, ${ }^{1029-3234-36394043-50}$ 52-56 58 61-65 67 6970 7275-79 82 which was 40.7 (SD 6.9) and 40.4 (SD 6.1), respectively. The percentage of women varied from $0 \%$ to $59.6 \%$. Average stone size was reported by treatment group in 41 studies, ${ }^{10} 29-3234-363940$ 43-56 58 60-67 69-727576787982 with a mean of 5.7 (SD 1.2) $\mathrm{mm}$ in the treatment group and 5.7 (SD 1.1) $\mathrm{mm}$ in the control group. While most studies were limited to patients with lower ureteric stones, 11 studies included stones located in the upper and middle ureter. ${ }^{1038404959606368697779}$

Table B in appendix 2 shows the interventions and follow-up, as well as the primary and secondary outcomes and recorded adverse events, from all included studies. Most studies had two arms, but 10 had three arms, 43464752636568707178 and two had four arms. ${ }^{3438}$ Although tamsulosin was the most common intervention (40 studies), 102930 32-35 38-40 43 45-49 51-63 65-69 71 73-75 777881 additional alpha blockers were evaluated, including alfuzosin (six), 444752637276 doxazosin (four), 37414255

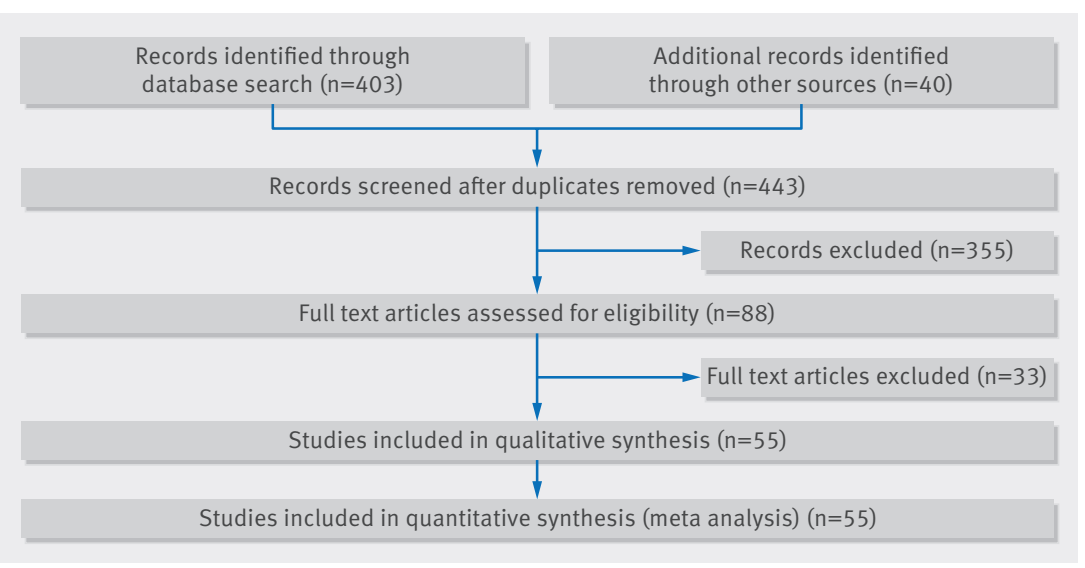

Fig 1 | PRISMA diagram of trials investigating efficacy of treatment with alpha blocker in patients with ureteric stones naftopidil (three), 506570 silodosin (six), 647178798082 and terazosin (four). ${ }^{31343646}$ The duration of follow-up varied across studies from seven to 42 days, with 28 days being the most common (37), $103031363740-45475153-5658-$ 6971727476-7981 or until stone passage. Placebo controls were used in 14 studies. ${ }^{1044} 47515356-5873-75798182$ In three studies, corticosteroids were given to the intervention and/or control groups. ${ }^{306568}$

The baseline rate of stone passage without treatment with an alpha blocker varied across countries (fig A in appendix 3), at 7\% in Thailand, 14\% in Sri Lanka, 80\% in the UK, and $82 \%$ in Australia.

Figure 2 summarizes the assessment of risk of bias for individual studies. Fifty two studies had at least one domain judged as unclear risk of bias, nine of which had at least one domain considered at high risk. 32435560 6369757682 Only three had all bias domains judged as low risk. ${ }^{105379}$ Eight studies were explicit about the reporting of an appropriate method of allocation concealment, ${ }^{1044535865787981}$ and only six studies reported blinding of outcome assessors. ${ }^{102953757981}$

\section{Effect of alpha blockers on passage of ureteric stones}

The random effects pooled risk ratio (and 95\% confidence interval estimated with the profile likelihood method) was 1.49 (1.39 to 1.61), indicating a 49\% higher risk of stone passage associated with treatment with an alpha blocker (fig 3). The 95\% confidence interval obtained with the restricted maximum likelihood method was similar (1.39 to 1.59). The quality of evidence for stone passage was rated "moderate" according the GRADE approach (table 1). The pooled risk difference was 0.27 (0.22 to 0.31). In other words, four patients would need treatment for one patient to realize benefit from alpha blockers. The prediction interval for the pooled risk ratio was 1.12 to 1.86 . The pooled percentages for stone passage in the intervention and control groups were $75.8 \%$ (72.1\% to $79.2 \%)$ and $48.4 \%$ ( $43.5 \%$ to $53.1 \%$ ), respectively. When the follow-up time was held constant at 28 days, these pooled percentages were $75.8 \%$ ( $71.4 \%$ to $80.0 \%$ ) and $48.2 \%$ (42.0\% to $54.4 \%)$, respectively.

In a cumulative meta-analysis, where we added studies one at a time (based on the publication date) and summarized the pooled risk ratio of ureteric stone passage as each new study was added, we observed a fairly stable pattern since 2006 (fig B in appendix 3). We saw no significant Proteus effect $(\mathrm{P}=0.32)$.

To determine if the effect size varied by the type of alpha blocker used, we performed meta-regression. There were no significant differences between the risk ratios for tamsulosin compared with alfuzosin $(\mathrm{P}=0.96)$, doxazosin $(\mathrm{P}=0.91)$, naftopidil $(\mathrm{P}=0.31)$, silodosin $(\mathrm{P}=0.37)$, or terazosin $(\mathrm{P}=0.88)$.

Not all studies reported on the use of imaging during follow-up. When we restricted analysis to studies in which computed tomography was used, 29445152586065676 9727981 the pooled risk ratio for stone passage was 1.64 (95\% confidence interval 1.31 to 2.16 ). When we restricted analysis to studies reporting any imaging 


\begin{tabular}{|c|c|c|c|c|c|c|c|c|c|c|c|}
\hline - Low risk of bias & & & & & & & & & & & \\
\hline Unclear risk of bias & & & & & & & & & & & \\
\hline High risk of bias & 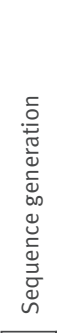 & 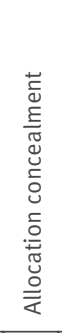 & 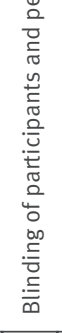 & 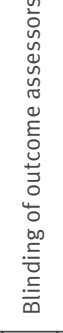 & 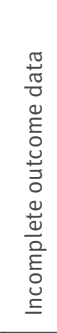 & Study & 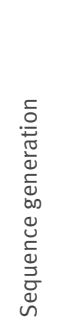 & 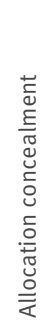 & 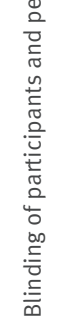 & 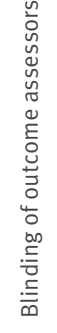 & $\begin{array}{l}\frac{\pi}{\pi} \\
\frac{\pi}{0}\end{array}$ \\
\hline bdel-Meguid $2010^{51}$ & ? & ? & $\odot$ & ? & $\odot$ & Kupeli $2004^{29}$ & 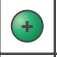 & ? & ? & 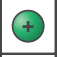 & 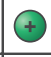 \\
\hline Abhishek $2015^{73}$ & ? & ? & $\odot$ & ? ? & $\odot$ & Lee $2014^{69}$ & ? & (?) & $\Theta$ & $\Theta$ & $\Theta$ \\
\hline rawal $2009^{47}$ & ? & ? & ? & ?? & $\odot$ & Liatsikos $2007^{41}$ & ? & ? & ? & ? & ? \\
\hline Ahmad $2015^{74}$ & ? & ? & $\oplus$ & ? & $\odot$ & Lojanapiwat $2008^{43}$ & ? & $\Theta$ & $\Theta$ & $\Theta$ & 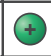 \\
\hline Ahmad $2010^{52}$ & ? & ? & ?? & ?? & $\odot$ & Lojanapiwat $2012^{59}$ & ? & ? & ? & ? & ? \\
\hline Al-Ansari $2010^{53}$ & $\oplus$ & $\oplus$ & $\oplus$ & $\oplus$ & $\odot$ & Lv $2014^{70}$ & ? & (?) & ? & ? & $\oplus$ \\
\hline Alizadeh $2014^{66}$ & ? & ? & ?? & ? & ? & Mohseni $2006^{36}$ & ? & (?) & ? & ? & 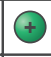 \\
\hline Aravinthan $2012^{57}$ & ? & ? & 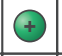 & (?) & ? & Mukhtarov & ? & (?) & ? & ? & $?$ \\
\hline Ayubov $2007^{37}$ & ? & ? & ? & (?) & ? & Ochoa-Gomez $2011^{56}$ & ? & ? & $\oplus$ & ? & † \\
\hline Bajwa $2013^{62}$ & $\oplus$ & ? & ?? & ? & $\odot$ & $12^{60}$ & ? & (?) & ? & ? & $\Theta$ \\
\hline Bak $2007^{38}$ & ? & ? & ? & (?) & $\odot$ & Pedro $2008^{44}$ & $\oplus$ & $\oplus$ & $\oplus$ & ? & $\oplus$ \\
\hline Balci $2014^{67}$ & $\oplus$ & ? & ? & ? & $\odot$ & Pickard $2015^{10}$ & ๑ & † & $\oplus$ & $\oplus$ & † \\
\hline Berger $2015^{75}$ & ? & ? & $\odot$ & $\odot$ & $\Theta$ & Porpiglia $2004^{30}$ & ? & ? & ? & ? & † \\
\hline Desai $2014^{68}$ & ? & ? ? & ?? & ?? & $\odot$ & Rahim $2012^{61}$ & $\odot$ & ? & ? & ? & 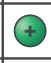 \\
\hline De Sio $2006^{35}$ & 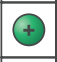 & ? & ?? & ? & $\odot$ & Rathi $2014^{71}$ & ?? & ?? & ? & ?? & ? \\
\hline El-Gamal $2012^{58}$ & 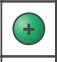 & $\oplus$ & 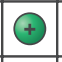 & (?) & $\odot$ & Resim $2005^{32}$ & ?? & (?) & $\odot$ & ?? & 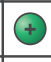 \\
\hline El Said $2015^{76}$ & $\oplus$ & ? & $\Theta$ & $\Theta$ & $\odot$ & Sameer $2014^{72}$ & ? & ? & ? & ? & $\odot$ \\
\hline Ertuhan $2007^{39}$ & ? & ? & ? & ? ? & $\odot$ & Sayed $2008^{45}$ & ? & (?) & ? & ? & $\oplus$ \\
\hline Eryildirim $2015^{77}$ & $\oplus$ & ? & ? & ? ? & ? & Sun $2009^{50}$ & ? & ? & ? & ? & $\odot$ \\
\hline Ferre $2009^{48}$ & $\oplus$ & ? & ? & ? & $\odot$ & Sur $2015^{79}$ & $\oplus$ & † & $\oplus$ & $\oplus$ & $\odot$ \\
\hline Furyk $2015^{81}$ & $\oplus$ & $\oplus$ & $\oplus$ & $\oplus$ & ? & Taghavi $2005^{33}$ & ? & ?? & ? & ? & ? \\
\hline Georgescu $2015^{78}$ & ? & $\oplus$ & ?? & (?) & $\odot$ & Tekin $2004^{31}$ & ?? & (?) & ?? & ? & ? \\
\hline Ibrahim $2013^{63}$ & ? & ? & ?? & ? & $\Theta$ & Wang $2008^{46}$ & 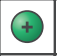 & ? & ? & ? & 3 \\
\hline Itoh $2013^{64}$ & $\oplus$ & ? & ?? & ?? & $\odot$ & Wang $2016^{82}$ & 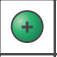 & ? & $\odot$ & ? & 0 \\
\hline Kaneko $2010^{54}$ & $\odot$ & ? & ? & ? & ? & Yilmaz $2005^{34}$ & $?$ & ?? & ? & ? & $\oplus$ \\
\hline Kang $2009^{49}$ & ? & ? & ?? & (?) & ? & Yuksel $2015^{80}$ & ? & (?) & ? & ? & $\oplus$ \\
\hline $\operatorname{Kim} 2007^{40}$ & ? & ? ? & ? & ? & ? & Zehri $2010^{55}$ & $\Theta$ & $\odot$ & $\Theta$ & ? & $\oplus$ \\
\hline Kumar $2013^{65}$ & $\oplus$ & $\odot$ & ? & ?? & $\odot$ & & & & & & \\
\hline
\end{tabular}

Fig 2 | Risk of bias summary showing study team's judgments about each risk of bias domain

during follow-up (computed tomography, radiography, or ultrasonography), ${ }^{29} 3032343639$ 40-47 50-61 63 65-70 $72747678-82$ the pooled risk ratio was 1.54 (1.41 to 1.70 ).

Regarding stone size, we observed no benefit to treatment with an alpha blocker among patients with smaller ureteric stones (fig 4 ; pooled risk ratio 1.19, 95\% confidence interval 1.00 to 1.48$)$. Patients with larger stones who received an alpha blocker, however, had a $57 \%$ higher risk of stone passage compared with controls (1.57, 1.17 to 2.27). Results from meta-regression indicated that there was a $9.8 \%$ increase in the risk ratio for stone passage for every $1 \mathrm{~mm}$ increase in stone size (2.5\% to $17.7 \%$; $<<0.01$ ). With respect to stone location (fig 5), the pooled risk ratio was 1.48 (1.05 to 2.10) for upper or middle ureteric stones and 1.49 (1.38 to 1.63) for lower ureteric stones.

\section{Sensitivity analyses}

There was statistical heterogeneity in the risk ratio for passage of ureteric stones across studies $\left(\tau^{2}=0.03,95 \%\right.$ confidence interval 0.0 to $0.06 ; \mathrm{I}^{2}=60,46.6 \%$ to $70.4 \%$ ). When we considered only those studies involving placebo controls, the pooled risk ratio was attenuated (1.32, 1.14 to 1.59), but significant heterogeneity remained $\left(\tau^{2}=0.05 ; \mathrm{I}^{2}=82 \%\right)$. Exclusion of studies in which corticosteroids were co-administered had little impact on our summary findings $(1.47,1.37$ to 1.59$)$ and explained little of the heterogeneity $\left(\tau^{2}=0.03 ; \mathrm{I}^{2}=59 \%\right)$. In analyses restricted to full length, peer reviewed research articles, 10293032343536 38-41 43-56 58 61-67 69 70 72 74 75-82 the pooled risk ratio 1.47 (1.36 to 1.61$)$ and heterogeneity $\left(\tau^{2}=0.04 ; I^{2}=64 \%\right)$ were stable.

In meta-regression, there was no significant association between maximum follow-up and stone passage $(P=0.71)$. There also was no association between sex and stone passage $(\mathrm{P}=0.85)$. Baseline risk (stone passage in patients not treated with an alpha blocker), however, did explain some of variation in effect across the studies (fig 3). The pooled risk ratio was 2.11 (95\% confidence interval 1.72 to 2.65; $\tau^{2}=0.07 ; \mathrm{I}^{2}=44 \%$ ) for trials with a baseline risk of $<40 \%$, 294347495055 57-60 $6265677275-771.52$ (1.40 to 1.63; $\tau^{2}<0.001 ; \mathrm{I}^{2}=0 \%$ ) for trials with a baseline risk of 40-60\%, $303133-3538-41454651525461636469717374787982$ and 1.20 (1.10 to $1.32 ; \tau^{2}=0.01 ; \mathrm{I}^{2}=56 \%$ ) for trials with a baseline risk of $>60 \%{ }^{1032363742444853566668708081}$

When we regressed baseline risk on the log of the risk ratio for passage of ureteric stones, there was a significant inverse linear association (fig $\mathrm{C}$ in appendix 3). For every $10 \%$ increase in the baseline risk, the relative risk of passage decreased by $13 \%(\mathrm{P}<0.01)$. Among studies in which the baseline risk was high, those by Pickard and colleagues, ${ }^{10}$ Furyk and colleagues, ${ }^{81}$ and Desai and colleagues ${ }^{68}$ were noted to be most influential on our pooled estimate of stone passage (fig D in appendix 3). With omission of the study by Pickard and colleagues, the pooled risk ratio was 1.23 (1.13 to 1.35; $\left.\tau^{2}=0.01 ; I^{2}=38 \%\right)$. With removal of the Furyk and Desai studies, the pooled risk ratios were 1.22 (1.12 to 1.35; $\tau^{2}=0.01 ; I^{2}=50 \%$ ) and 1.17 ( 1.08 to $1.30 ; \tau^{2}=0.01 ; I^{2}=50 \%$ ), respectively.

In a further sensitivity analysis, we recalculated our summary estimates including only moderate and low risk of bias. The beneficial effect of treatment with alpha blockers on passage of ureteric stones persisted, but its magnitude was diminished (13 studies, 2469 patients: pooled risk ratio $1.33,95 \%$ confidence interval 1.15 to $\left.1.59 ; \tau^{2}=0.04 ; I^{2}=79 \%\right) .{ }^{1029515356586573-75787981}$ 


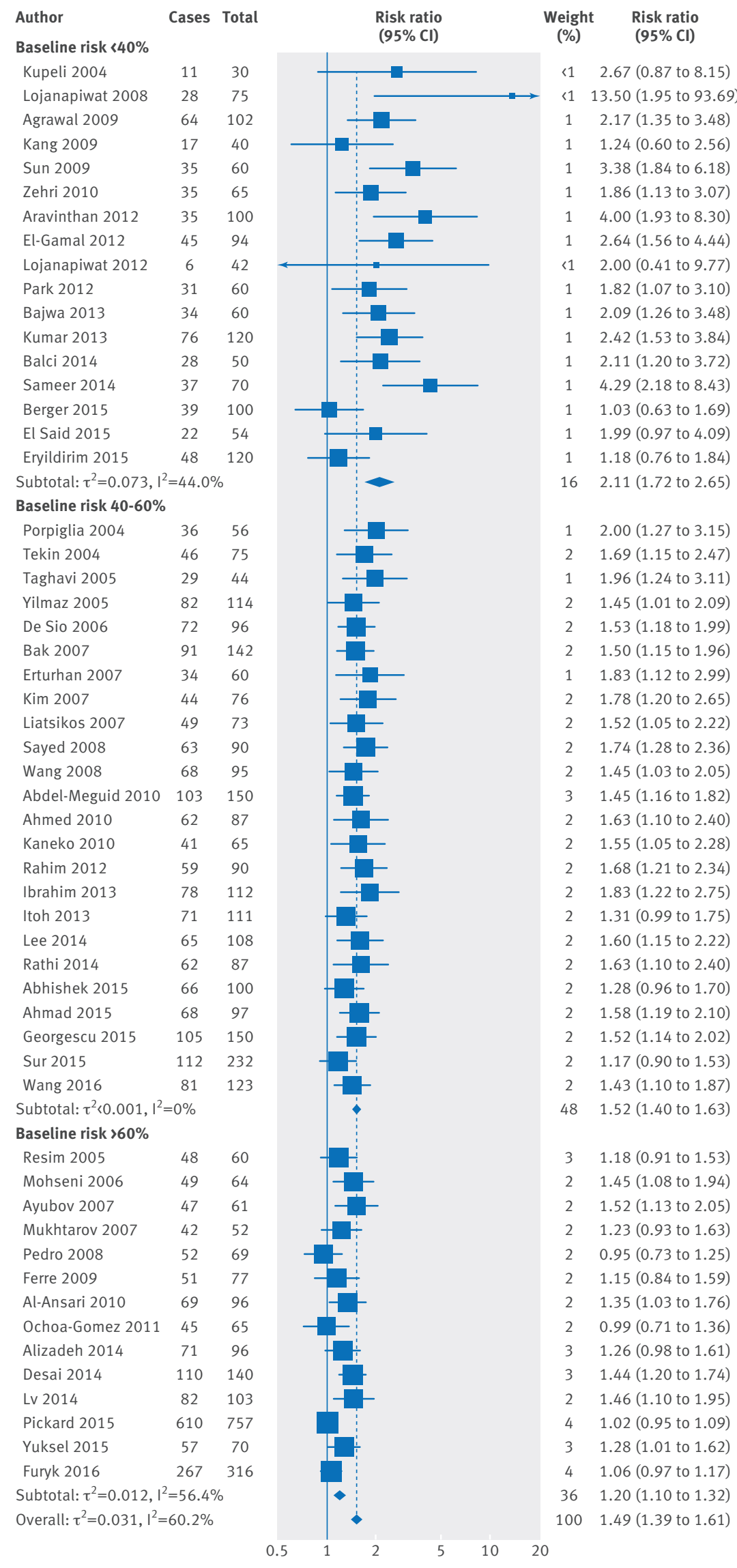

Fig 3 | Risk ratios for passage of ureteric stones in randomized controlled trials on efficacy of treatment with alpha blockers, stratified by baseline risk

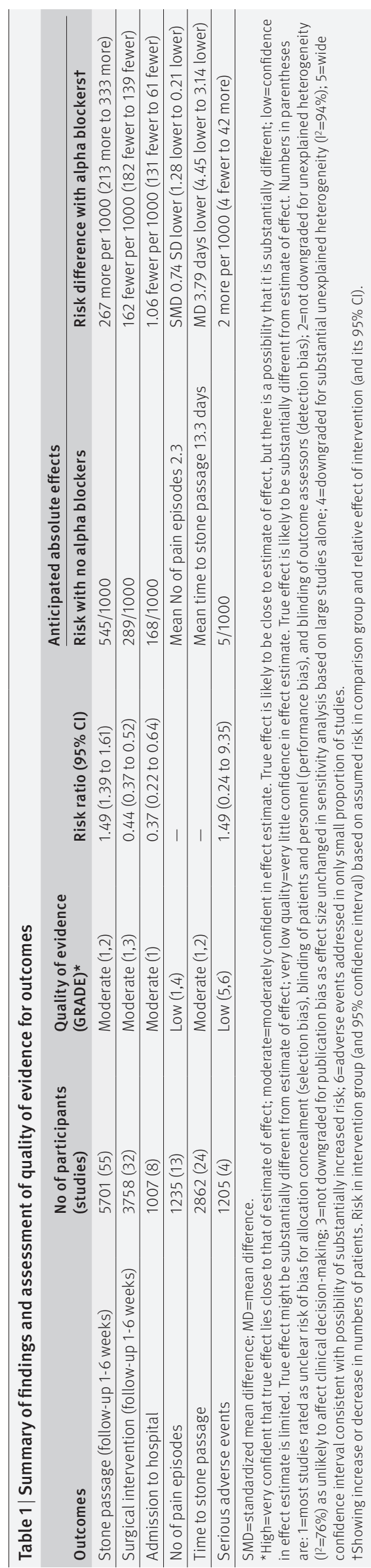

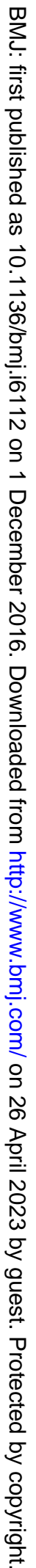




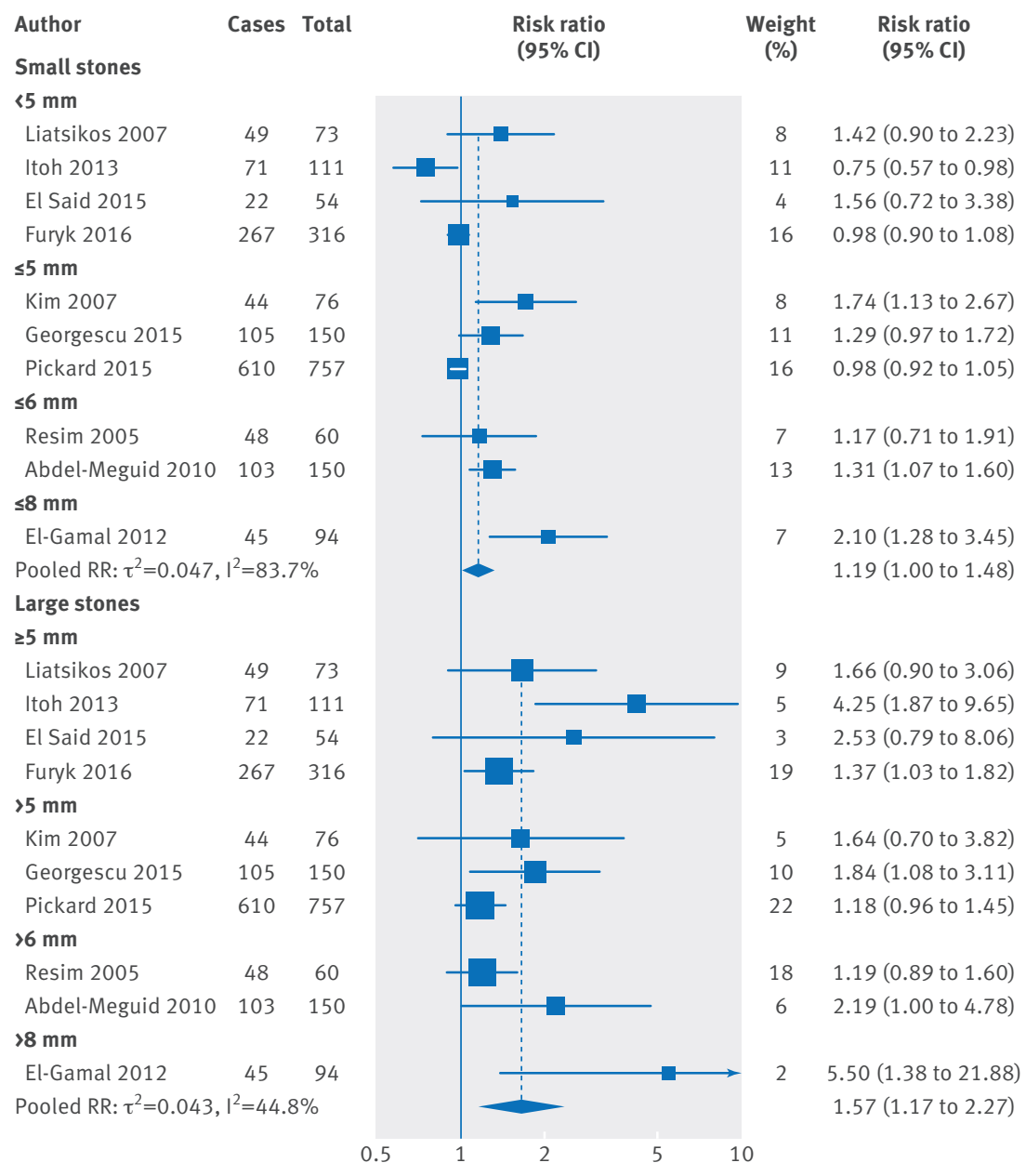

Fig 4 | Risk ratios for passage of ureteric stones in randomized controlled trials on efficacy of treatment with alpha blockers, stratified by stone size
Twenty four studies reported data regarding time to stone passage (means and standard deviations). ${ }^{1034-}$ 3640 44-46 52-5456 61 62 64-66 6970717278 8082 Figure F in appendix 3 shows that treatment with an alpha blocker was associated with an overall shorter time to stone passage (2862 patients: pooled mean difference -3.79 days, $95 \%$ confidence interval -4.45 to $-3.14 ; \tau^{2}=1.42, I^{2}=74 \%$; moderate quality evidence). Mean time to stone passage (unweighted) was 8.8 and 13.3 days in the treatment and control groups, respectively. Figure $\mathrm{F}$ in appendix 3 shows that there was also a significant difference in the mean number of episodes of pain, favoring treatment with an alpha blocker (13 studies, 1235 patients: -0.74 episodes, -1.28 to $-0.21 ; \tau^{2}=0.78 ; I^{2}=94 \%$; low quality evidence). $3234454652536570-72778082$ Figure $\mathrm{H}$ in appendix 3 shows that patients treated with an alpha blocker needed admission to hospital less often than controls (8 studies, 1007 patients: pooled risk ratio $0.37,0.22$ to $0.64 ; \quad \tau^{2}=0.23 ; \quad I^{2}=39 \%$; moderate quality evidence). ${ }^{3539527274767881}$ Five studies reported no patients needing admission in either the treatment or control groups and were excluded. 3037465082

Adverse events were uncommon among treatment and control groups (fig I, appendix 3). Men receiving alpha blockers were more likely than male controls to experience abnormal ejaculation (pooled risk ratio $4.09,95 \%$ confidence interval 1.73 to 12.04 ). The risk of a serious adverse event, however, was similar between the two groups (1.49, 0.24 to 9.35; low quality evidence).

\section{Risk of publication bias}

Inspection of the funnel plots showed asymmetry (fig J, appendix 3), indicating evidence of a small study effect for stone passage (Harbord's test: $\mathrm{P}<0.01$ ), surgical intervention (Harbord's test: $\mathrm{P}<0.01$ ), and pain (Egger's test: $\mathrm{P}=0.01$ ), but not for time to stone passage (Egger's test: $\mathrm{P}=0.40$ ) or admission to hospital (Harbord's test: $\mathrm{P}=0.48)$. Thus, we calculated the pooled risk ratio only for large studies (sample size $\geq 100$ ). ${ }^{10} 343847515763-6568$ $70737577-798182$ This yielded a pooled risk ratio of 1.39 (95\% confidence interval 1.26 to 1.58 ) for stone passage and $0.46(0.33$ to 0.60$)$ for surgery.

\section{Discussion}

\section{Statement of principal findings}

The pooled results of the randomized controlled trials suggest that alpha blockers help facilitate the passage of larger ureteric stones regardless of their location. Given the low risk profile of these drugs and their wide therapeutic window, our findings suggest that clinicians who manage patients with ureteric colic should consider prescribing a course of an alpha blocker, unless it is medically contraindicated.

Our findings on the effectiveness of medical expulsive therapy as it relates to the size of ureteric stones have face validity. Data from several observational studies suggest that nearly all smaller ureteric stones (that is, $<5 \mathrm{~mm}$ ) will pass without difficulty. ${ }^{83} 84$ The expected benefit of medical expulsive therapy (for augmenting stone passage) is therefore probably minimal in this subgroup. Along these lines, our findings corroborate 


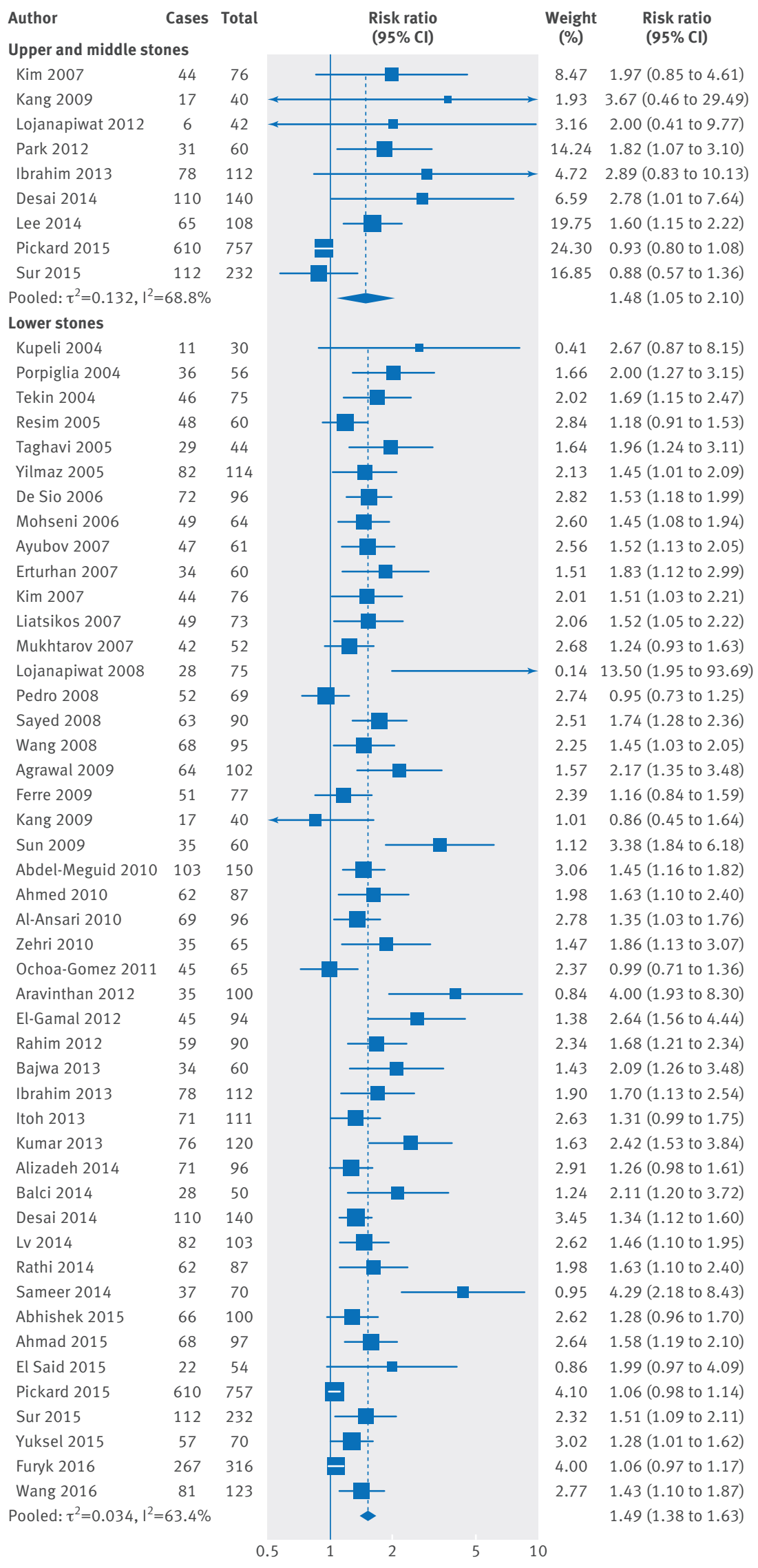

Fig 5 Risk ratios for passage of ureteric stones in randomized controlled trials on efficacy of treatment with alpha blockers, stratified by stone location results from another high profile randomized controlled trial reported by Furyk and colleagues, ${ }^{81}$ which was published shortly after the Pickard study. ${ }^{10}$ This double blind, placebo controlled, multicenter trial from Australia found no benefit overall of treatment with an alpha blocker for patients with lower ureteric calculi $\leq 10 \mathrm{~mm}$ in terms of spontaneous passage; however, in a prespecified subgroup analysis of large stones (5-10 mm), use of tamsulosin was associated with significantly higher rates of passage.

Regarding location of ureteric stones, our findings contrast with those from a rigorous randomized controlled trial conducted by Sur and colleagues. ${ }^{79}$ Despite the fact that use of sildosin achieved a significantly greater rate of passage of lower ureteric stones than placebo, this trial showed no benefit to treatment for stones in the upper and middle ureter (because of wide confidence intervals around the effect estimates), but there was a consistent trend towards benefit. The effects of alpha blockers on passage are thought to result from relaxation of ureteric smooth muscle mediated by binding of the drug to alpha adrenergic receptors in the region of the stone. Yet, while alpha adrenergic receptors are concentrated in the lower ureter, ${ }^{85}$ studies have shown that they are present along the entire length of the human ureter. ${ }^{8687}$ Thus, one could anticipate that alpha blockers exert their effect throughout the ureter, as we found in our pooled analysis.

\section{Strengths and weaknesses of study}

The strengths of our study include the comprehensive nature of our literature search (which included studies irrespective of language and publication status); the thoroughness of our study selection, data abstraction, and risk of bias assessment (carried out in duplicate by two independent members of our study team); our predefined analytic plan; and our use of the GRADE approach for assessing the quality of evidence on an outcome specific basis.

Despite these strengths, several limitations merit discussion. The first relates to clinical (not statistical) heterogeneity between pooled studies, in view of the variation in the types of alpha blockers given, the inconsistent use of post-treatment imaging, and differential follow-up. We found, however, that the pooled relative risk of passage of ureteric stones was independent of these clinical differences. Another limitation pertains to the overall methodological rigor of the pooled studies. Only a handful concealed allocation adequately, and just six studies reported blinding of outcome assessment. Given that the inclusion of less rigorous studies could lead to misestimation of the true intervention effect, we conducted separate sensitivity analyses, in which we recalculated our summary estimates excluding data from non-placebo controlled studies and those in which the risk of bias was judged high. While our summary estimates were attenuated, the benefit of alpha blockers persisted. Differences in stone passage by type of alpha blocker were not found through meta-regression, but this could be because of insufficient power. Finally, our results could be affected 
by publication bias, whereby smaller studies with negative results might never have been published. To account for this possibility, we repeated our models pooling data from only larger studies and found our results to be robust.

\section{Strengths and weaknesses in relation to other studies}

Several previous systematic reviews and meta-analyses have examined the role of alpha blockers for treatment of ureteric stones, most notably the initial study by Hollingsworth and colleagues. ${ }^{3}$ They identified nine randomized controlled trials that yielded a pooled risk ratio of 1.54 (95\% confidence interval 1.29 to 1.85 ), favoring medical expulsive therapy. The recent Cochrane review published by Campshroer and colleagues included 32 randomized controlled trials and found a $48 \%$ higher risk of stone passage with treatment with alpha blockers than control (risk ratio $1.48,1.33$ to 1.64). ${ }^{6}$ Similar to our findings, the benefit of alpha blockers was attenuated when the analysis was limited to only four placebo controlled trials (1.22, 0.99 to 1.55$)$ but consistent with a potentially large effect.

Since the date of the Cochrane group's last search, we identified 24 additional randomized controlled trials on alpha blockers for the treatment of ureteric stones. We are unaware of any recent high quality systematic reviews that include the randomized controlled trial from Pickard and colleagues, findings from which have called the concept of medical expulsive therapy into question. ${ }^{10}$ Although the Pickard study was large and methodologically rigorous in its design, its results need to be placed into the context of the entire body of evidence as in a systematic review like ours. We can explain the discrepancies in findings largely due to the high rate of spontaneous stone passage in the control arm of the trial perhaps because of the large proportion of patients with smaller stones.

A second important difference between the Pickard study and most other randomized controlled trials on medical expulsive therapy relates to how stone passage was defined. Imaging evidence has been the standard assessment, yet investigators in the Pickard study chose instead "absence of need for additional interventions to assist stone passage at four weeks after randomisation."10 Compelling arguments can be made that this endpoint is highly relevant to surgeons, but the degree to which intervention rates accurately approximate spontaneous stone passage is uncertain. While additional imaging was obtained when "clinically indicated" (such as for continued pain, development of infection), just over half of participants were reimaged, raising the possibility of silent obstruction and late secondary complications. ${ }^{88}$ Further, defining passage by the absence of intervention, rightly or wrongly, does not reflect routine clinical practice in many countries outside the UK, nor does it align with contemporary practice guidelines from the European Association of Urology, under which reimaging is recommended to monitor the position of ureteric stones and assess for hydronephrosis.

\section{Implications for clinicians and policy makers}

Findings from our study emphasize the role of systematic reviews to examine focused clinical questions. The recent publication of the Pickard study brought into question the effectiveness of alpha blockers in patients with ureteric colic, leading to calls from the urologic community to reformulate treatment guidelines and even abandon medical expulsive therapy altogether. Our findings suggest that this would be an over-reaction as large subgroups of patients could be spared from stone surgery and its attendant risks with a trial of an alpha blocker.

Further, our study highlights the challenges of trials with undifferentiated cohorts that often lack the sample size necessary to tease out important clinical nuances. Therefore, while not all patients seen in the emergency department for ureteric colic will be helped by alpha blockers, our meta-analysis, which draws power from the pooling of data across multiple studies, suggests that those with stones $\geq 5 \mathrm{~mm}$ in size could.

Such a size based approach to the use of alpha blockers requires patients with suspected ureteric stones to undergo radiologic testing. Under current guidelines on urolithiasis from the European Association of Urology, immediate imaging is indicated in the evaluation of all patients who present with acute flank pain. ${ }^{2}$ In many emergency departments, however, particularly for patients with known histories of urinary stone disease, imaging is often deferred until the time of primary or specialty care follow-up, which could delay initiation of expulsive therapy. Moreover, renal ultrasonography is often used as the primary diagnostic tool, from which stone size cannot always be accurately assessed. While a non-contrast computed tomogram should be obtained subsequently to confirm a stone diagnosis, ${ }^{2}$ many times it is not. Clearly, there are some clinical challenges for the implementation of our findings.

\section{Unanswered questions and future research}

Our findings on international differences in the baseline rates of stone passage suggest that patient related factors could modify the effects of expulsive therapy. To better assess their role, investigators could consider including variables like patient age, sex, and race/ethnicity in the design of a large international trial. Future studies should also examine patients' values and preferences concerning acceptable risk of retained ureteric stones versus the potential inconvenience, radiation exposure, and the direct and indirect costs of repeat imaging.

Contributors: JMH and BKC are joint first authors. All authors were involved in the conception and design of the review. JMH, BKC, GMK, and PD developed the search strategy and performed study selection. JMH, BKC, SS, PY, and PD extracted data from included studies. MAMR and PY were involved in the data analysis. JMH, BKC, MAMR, PY, and PD were involved in the interpretation and discussion of results. JMH drafted the manuscript, and MAMR, PY, and PD contributed to the drafting of the review. BKC, SS, and GMK revised it critically for important intellectual content. All authors approved the final version of the article. All authors had access to all of the data in the study and can take responsibility for the integrity of the data and the accuracy of the data analysis. JMH is guarantor. 
Funding: This research received no specific grant from any funding agency in the public, commercial, or not-for-profit sectors.

Competing interests: All authors have completed the ICMJE uniform disclosure form at http://www.icmje.org/coi_disclosure.pdf and declare: JMH received research grants from the Agency for Healthcare Research and Quality, the Urology Care Foundation, and Blue Cross Blue Shield of Michigan during the conduct of this study.

Ethical approval: Not required.

Data sharing: No additional data available.

Transparency: The lead author affirms that the manuscript is an honest, accurate, and transparent account of the study being reported; no important aspects of the study have been omitted

This is an Open Access article distributed in accordance with the Creative Commons Attribution Non Commercial (CC BY-NC 3.0) license, which permits others to distribute, remix, adapt, build upon this work non-commercially, and license their derivative works on different terms, provided the original work is properly cited and the use is non-commercial. See: http://creativecommons.org/licenses/ by-nc/3.0/

1 Preminger GM, Tiselius HG, Assimos DG, et al. EAU/AUA Nephrolithiasis Guideline Panel. 2007 guideline for the management of ureteral calculi. J Urol 2007;178:2418-34 doi:10.1016/j.juro.2007.09.107.

2 Türk C, Petřík A, Sarica K, et al. EAU Guidelines on Diagnosis and Conservative Management of Urolithiasis. Eur Urol 2016;69:468-74. doi:10.1016/i.eururo.2015.07.040

3 Hollingsworth JM, Rogers MA, Kaufman SR, et al. Medical therapy to facilitate urinary stone passage: a meta-analysis. Lancet 2006;368:1171-9. doi:10.1016/S0140-6736(06)69474-9.

4 Singh A, Alter HJ, Littlepage A. A systematic review of medical therapy to facilitate passage of ureteral calculi. Ann Emerg Med 2007;50:55263. doi:10.1016/j.annemergmed.2007.05.015.

5 Lu Z, Dong Z, Ding H, Wang H, Ma B, Wang Z. Tamsulosin for ureteral stones: a systematic review and meta-analysis of a randomized controlled trial. Urol Int 2012;89:107-15. doi:10.1159/000338909.

6 Campschroer T, Zhu Y, Duijvesz D, Grobbee DE, Lock MT. Alpha-blockers as medical expulsive therapy for ureteral stones. Cochrane Database Syst Rev 2014;4:CD008509. doi:10.1002/14651858.CD008509.pub2.

7 Huang W, Xue P, Zong H, Zhang Y. Efficacy and safety of silodosin in the medical expulsion therapy for distal ureteral calculi: a systematic review and meta-analysis. BrJ Clin Pharmacol 2016;81:13-22. doi: $10.1111 /$ bcp.12737.

8 Özsoy M, Liatsikos E, Scheffbuch N, Kallidonis P. Comparison of silodosin to tamsulosin for medical expulsive treatment of ureteral stones: a systematic review and meta-analysis. Urolithiasis 2016;44:491-7. doi:10.1007/s00240-016-0872-y.

9 Liu C, Zeng G, Kang R, et al. Efficacy and safety of alfuzosin as medical expulsive therapy for ureteral stones: a systematic review and meta-analysis. PLoS One 2015;10:e0134589. doi:10.1371/journal. pone.0134589.

10 Pickard R, Starr K, MacLennan G, et al. Medical expulsive therapy in adults with ureteric colic: a multicentre, randomised, placebocontrolled trial. Lancet 2015;386:341-9. doi:10.1016/ S0140-6736(15)60933-3.

11 Van Asseldonk B, Elterman DS. Medical Expulsive Therapy for Ureteric Colic: New Hard Evidence: Commentary on: Medical expulsive therapy in adults with ureteric colic: a multicentre, randomised, placebo-controlled trial. Urology 2015;86:649-50. doi:10.1016/j.urology.2015.06.030

12 Preminger GM, Bell JR, Nakada SY. Medical expulsive therapy is useful for urinary calculi. J Urol 2016;195:554-6. doi:10.1016/j.juro.2015.12.066.

13 Ambani SN, Ghani KR. Stones in 2015: Changes in stone management - suspending belief for evidence. Nat Rev Urol 2016;13:71-2. doi:10.1038/nrurol.2015.290.

14 Bultitude M. The drugs don't work. BJU International Web site. 19 May 2015. http://www.bjuinternational.com/bjui-blog/ the-drugs-dont-work/.

15 Liberati A, Altman DG, TetzlaffJ, et al. The PRISMA statement for reporting systematic reviews and meta-analyses of studies that evaluate healthcare interventions: explanation and elaboration. $B M$ 2009;339:b2700. doi:10.1136/bmj.b2700.

16 Higgins JP, Altman DG, Gøtzsche PC, et al. Cochrane Bias Methods Group Cochrane Statistical Methods Group. The Cochrane Collaboration's tool for assessing risk of bias in randomised trials. $B M$, 2011;343:d5928. doi:10.1136/bmi.d5928.

17 Freeman MF, Tukey JW. Transformations related to the angular and the square root. Ann Math Stat 1950;21:607-11doi:10.1214/ aoms/1177729756.

18 Cornell JE, Mulrow CD, Localio R, et al. Random-effects meta-analysis of inconsistent effects: a time for change. Ann Intern Med 2014;160:267-70. doi:10.7326/M13-2886.

19 Hartung J, Knapp G. On tests of the overall treatment effect in meta-analysis with normally distributed responses. Stat Med 2001;20:1771-82. doi:10.1002/sim.791.
20 Hartung J, Knapp G. A refined method for the meta-analysis of controlled clinical trials with binary outcome. Stat Med 2001;20:387589. doi:10.1002/sim.1009.

21 IntHout J, loannidis JP, Borm GF. The Hartung-Knapp-Sidik-Jonkman method for random effects meta-analysis is straightforward and considerably outperforms the standard DerSimonian-Laird method. BMC Med Res Methodol 2014:14:25. doi:10.1186/1471-2288-14-25.

22 loannidis JPA, Trikalinos TA. Early extreme contradictory estimates may appear in published research: the Proteus phenomenon in molecular genetics research and randomized trials. / Clin Epidemiol 2005;58:543-9. doi:10.1016/j.jclinepi.2004.10.019.

23 IntHout J, loannidis JP, Rovers MM, Goeman JJ. Plea for routinely presenting prediction intervals in meta-analysis. BMJ Open 2016;6:e010247. doi:10.1136/bmjopen-2015-010247.

24 Brockwell SE, Gordon IR. A comparison of statistical methods for meta-analysis. Stat Med 2001;20:825-40. doi:10.1002/sim.650.

25 Higgins JP, Thompson SG. Quantifying heterogeneity in a metaanalysis. Stat Med 2002;21:1539-58. doi:10.1002/sim.1186.

26 Rücker G, Schwarzer G, Carpenter JR, Schumacher M. Undue reliance on I(2) in assessing heterogeneity may mislead. BMC Med Res Methodol 2008;8:79. doi:10.1186/1471-2288-8-79.

27 Harbord RM, Egger M, Sterne JAC. A modified test for small-study effects in meta-analyses of controlled trials with binary endpoints. Stat Med 2006:25:3443-57. doi:10.1002/sim.2380

28 Guyatt GH, Oxman AD, Vist GE, et al. GRADE Working Group. GRADE: an emerging consensus on rating quality of evidence and strength of recommendations. BMJ 2008;336:924-6. doi:10.1136/ bmj.39489.470347.AD.

29 Küpeli B, Irkilata L, Gürocak S, et al. Does tamsulosin enhance lower ureteral stone clearance with or without shock wave lithotripsy?Urology 2004;64:1111-5. doi:10.1016/j. urology.2004.07.020

30 Porpiglia F, Ghignone G, Fiori C, Fontana D, Scarpa RM. Nifedipine versus tamsulosin for the management of lower ureteral stones. J Urol 2004;172:568-71. doi:10.1097/01.ju.0000132390.61756.ff.

31 Tekin A, Alkan E, Beysel M, Yucebas E, Aslan R, Sengor F. Alpha-1 receptor blocking therapy for lower ureteral stones: a randomized prospective trial. /Urol 2004;171 (abstract 1152).http://www.ncbi.nlm.nih.gov/entrez/query. fcgi?cmd=Retrieve\&db=PubMed\&list_uids=14767290\&dopt=Abstract

32 Resim S, Ekerbicer H, Ciftci A. Effect of tamsulosin on the number and intensity of ureteral colic in patients with lower ureteral calculus. Int J Urol 2005;12:615-20. doi:10.1111/j.1442-2042.2005.01116.x.

33 Taghavi R, Darabi M, Tavakoli K, Keshvari M. Survey of the effect of tamsulosin and nifedipine on facilitating juxtavesical ureteral stone passage. J Endourol 2005;19(abstract MP03-06):A9.

34 Yilmaz E, Batislam E, Basar MM, Tuglu D, Ferhat M, Basar H. The comparison and efficacy of 3 different alpha1-adrenergic blockers for distal ureteral stones. / Urol 2005:173:2010-2. doi:10.1097/01. ju.0000158453.60029.0a.

35 De Sio M, Autorino R, Di Lorenzo G, et al. Medical expulsive treatment of distal-ureteral stones using tamsulosin: a single-center experience. J Endourol 2006;20:12-6. doi:10.1089/end.2006.20.12

36 Mohseni MG, Hosseini SR, Alizadeh F. Efficacy of terazosin as a facilitator agent for expulsion of the lower ureteral stones. Saudi Med / 2006;27:838-40.

37 Ayubov B, Arustamov D, Mukhtarov S. Efficacy of doxazosin in the management of ureteral stones. Eur Urol Suppl 2007:6:114doi:10.1016/S1569-9056(07)60367-4

38 Bak CW, Yoon SJ, Chung H. Effects of an $\alpha$-blocker and terpene mixture for pain control and spontaneous expulsion of ureter stone. Korean J Urol 2007;48:517-21doi:10.4111/kju.2007.48.5.517.

39 Erturhan S, Erbagci A, Yagci F, Celik M, Solakhan M, Sarica K. Comparative evaluation of efficacy of use of tamsulosin and/or tolterodine for medical treatment of distal ureteral stones. Urology 2007:69:633-6. doi:10.1016/j.urology.2007.01.009.

$40 \mathrm{Kim}$ JW, Cho DY, Lee JG. Effect of tamsulosin on the expected treatment of upper and lower ureteral stones. Korean J Urol 2007;48:72430doi:10.4111/kju.2007.48.7.724.

41 Liatsikos EN, Katsakiori PF, Assimakopoulos K, et al. Doxazosin for the management of distal-ureteral stones. J Endourol 2007;21:538-41. doi:10.1089/end.2006.0107.

42 Mukhtarov S, Turdiev A, Fozilov A, Arustamov D, Ayubov B. Using doxazosin for distal ureteral stone clearance with or without shock wave lithotripsy. Eur Urol Supp/ 2007;6:216doi:10.1016/ S1569-9056(07)60769-6.

43 Lojanapiwat B, Kochakarn W, Suparatchatpan N, Lertwuttichaikul K. Effectiveness of low-dose and standard-dose tamsulosin in the treatment of distal ureteric stones: a randomized controlled study. J Int Med Res 2008:36:529-36. doi:10.1177/147323000803600318.

44 Pedro RN, Hinck B, Hendlin K, Feia K, Canales BK, Monga M. Alfuzosin stone expulsion therapy for distal ureteral calculi: a double-blind, placebo controlled study. J Urol 2008;179:2244-7, discussion 2247. doi:10.1016/j.juro.2008.01.141.

45 Sayed MAB, Abolyosr A, Abdalla MA, El-Azab AS. Efficacy of tamsulosin in medical expulsive therapy for distal ureteral calculi. Scand I Urol Nephrol 2008;42:59-62. doi:10.1080/00365590701571076. 
46 Wang CJ, Huang SW, Chang CH. Efficacy of an alpha1 blocker in expulsive therapy of lower ureteral stones. J Endourol 2008;22:41-6. doi:10.1089/end.2007.0133.

47 Agrawal M, Gupta M, Gupta A, Agrawal A, Sarkari A, Lavania P. Prospective randomized trial comparing efficacy of alfuzosin and tamsulosin in management of lower ureteral stones. Urology 2009;73:706-9. doi:10.1016/j.urology.2008.11.013.

48 Ferre RM, Wasielewski JN, Strout TD, Perron AD. Tamsulosin for ureteral stones in the emergency department: a randomized, controlled trial. Ann Emerg Med 2009:54:432-9, 439.e1-2. doi:10.1016/j.annemergmed.2008.12.026

49 Kang DI, Cho WY, Kim TH, et al. Effect of tamsulosin $0.2 \mathrm{mg}$ on the short-term treatment of urinary stones: multicenter, prospective, randomized study. Korean J Urol 2009;50:586-90doi:10.4111/ kju.2009.50.6.586.

50 Sun X, He L, Ge W, Lv J. Efficacy of selective alpha1D-blocker naftopidil as medical expulsive therapy for distal ureteral stones. J Urol 2009;181:1716-20. doi:10.1016/j.juro.2008.11.118.

51 Abdel-Meguid TA, Tayib A, Al-Sayyad A. Tamsulosin to treat uncomplicated distal ureteral calculi: a double blind randomized placebo-controlled trial. Can J Urol 2010;17:5178-83.

52 Ahmed AF, Al-Sayed AY. Tamsulosin versus alfuzosin in the treatment of patients with distal ureteral stones: prospective, randomized, comparative study. Korean JUrol 2010:51:193-7. doi:10.4111/kju.2010.51.3.193.

53 Al-Ansari A, Al-Naimi A, Alobaidy A, Assadiq K, Azmi MD, Shokeir AA. Efficacy of tamsulosin in the management of lower ureteral stones: a randomized double-blind placebo-controlled study of 100 patients. Urology 2010;75:4-7. doi:10.1016/j.urology.2009.09.073.

54 Kaneko T, Matsushima H, Morimoto H, Tsuzaka Y, Homma Y. Efficacy of low dose tamsulosin in medical expulsive therapy for ureteral stones in Japanese male patients: a randomized controlled study. Int J Urol 2010;17:462-5. doi:10.1111/j.1442-2042.2010.02499.x.

55 Zehri AA, Ather MH, Abbas F, Biyabani SR. Preliminary study of efficacy of doxazosin as a medical expulsive therapy of distal ureteric stones in a randomized clinical trial. Urology 2010;75:1285-8. doi:10.1016/j. urology.2009.10.069.

56 Ochoa-Gómez R, Prieto-Díaz-Chávez E, Trujillo-Hernández B, Vásquez C. Tamsulosin does not have greater efficacy than conventional treatment for distal ureteral stone expulsion in Mexican patients. Urol Res 2011;39:491-5. doi:10.1007/s00240-011-0380-z.

57 Aravinthan T. The efficacy of tamsulosin in lower ureteral calculi. Int Urol 2012;19(suppl 1):5-458. doi:10.1111/j.1442-2042.2012.03167.x

58 El-Gamal O, El-Bendary M, Ragab M, Rasheed M. Role of combined use of potassium citrate and tamsulosin in the management of uric acid distal ureteral calculi. Urol Res 2012;40:219-24. doi:10.1007/ s00240-011-0406-6

59 Bannaki L. Role of tamsulosin as medical expulsive therapy for proximal ureteral calculi: a randomized controlled study. Int J Urol 2012;19(S1):64.

60 Park J, Joo HT, Whang HW, Lee SW. Effect of tamsulosin for stone expulsion and patient's quality of life in proximal ureteral calculi. J Endourol 2012;26:A106-06.

61 Rahim J, Mahmood A, Ashraf S, Tahir MM, Khan MU. Efficacy of tamsulosin spontaneous expulsion in the treatment of distal ureteric stones. Pak J Med Health Sci 2012;6:191-4.

62 Bajwa MS, Rahim J, Rahim J, et al. Efficacy of tamsulosin for clearance of lower ureteric stones. Pak J Med Health Sci 2013;7:769-72.

63 Ibrahim AK, Mahmood IH, Mahmood NS. Efficacy and safety of tamsulosin vs. alfuzosin as medical expulsive therapy for ureteric stones. Arab J Urol 2013;11:142-7. doi:10.1016/j.aju.2013.02.003.

64 Itoh Y, Okada A, Yasui T, et al. Administration of the selective alpha $1 \mathrm{~A}$-adrenoceptor antagonist silodosin facilitates expulsion of size 5-10 mm distal ureteral stones, as compared to control. Int Urol Nephrol 2013;45:675-8. doi:10.1007/s11255-013-0429-8.

65 Kumar S, Kurdia KC, Ganesamoni R, Singh SK, Nanjappa B. Randomized controlled trial to compare the safety and efficacy of naftopidil and tamsulosin as medical expulsive therapy in combination with prednisolone for distal ureteral stones. Korean J Urol 2013:54:311-5. doi:10.4111/kju.2013.54.5.311.

66 Alizadeh M, Magsudi M. The effect of tamsulosin in the medical treatment of distal ureteral stones. Glob J Health Sci 2014;6:44-8. doi:10.5539/gihs.v6n7p44.

67 Balci M, Tuncel A, Aydin O, et al. Tamsulosin versus nifedipin in medical expulsive therapy for distal ureteral stones and the predictive value of Hounsfield unit in stone expulsion. Ren Fail 2014;36:1541-4. doi:10.3109/0886022X.2014.959023.
68 Desai A, Patil N, Biradar A, Kundargi VS. Role of medical expulsive therapy in ureteric calculi. Indian J Urol 2014;30:S61-2.

69 Lee SW, Woo SH, Yoo DS, Park J. Effect of tamsulosin on stone expulsion in proximal ureteral calculi: an open-label randomized controlled trial. Int J Clin Pract 2014;68:216-21. doi:10.1111/ijcp.12271.

70 Lv LL, Tang QL. Comparative evaluation of efficacy of use of naftopidil and/or celecoxib for medical treatment of distal ureteral stones. Urolithiasis 2014;42:541-7. doi:10.1007/s00240-014-0708-6.

71 Rathi S, Agarwal A, Patnaik P, Shaw D, Trivedi S, Dwivedi US. Evaluation of medical expulsive therapy for distal ureteral stone: a prospective randomized controlled study to compare silodosin versus tamsulosin. Indian J Urol 2014;30:S83.

72 Sameer LS, Lal S, Charak KS, Chakravarti S, Kohli S, Ahmad S. Efficacy of nifedipine and alfuzosin in the management of distal ureteric stones: A randomized, controlled study. Indian J Urol 2014;30:387-91. doi:10.4103/0970-1591.139572.

73 Abhishek L, Shashikant M, Arvind G, Ravindra S, Mahesh D. Comparison of tadalafil and tamsulosin in medical expuslive therapy for ureteric calculus: prospective, randomized, placebo controlled study. Indian J Urol 2015;31:abstract CKP-03:S39.

74 Ahmad H, Azim W, Akmal M, et al. Medical expulsive treatment of distal ureteral stone using tamsulosin. J Ayub Med Coll Abbottabad 2015;27:48-50.

75 Berger DA, Ross MA, Hollander JB, et al. Tamsulosin does not increase 1 -week passage rate of ureteral stones in ED patients. Am J Emerg Med 2015;33:1721-4. doi:10.1016/j.ajem.2015.08.006.

76 El Said NO, El Wakeel L, Kamal KM, Morad AelR. Alfuzosin treatment improves the rate and time for stone expulsion in patients with distal uretral stones: a prospective randomized controlled study. Pharmacotherapy 2015;35:470-6. doi:10.1002/phar.1593.

77 Eryildirim B, Sahin C, Tuncer M, et al. Effect of medical expulsive therapy on the health-related quality of life of patients with ureteral stones: a critical evaluation. Int Urol Nephrol 2015;47:1271-5. doi:10.1007/s11255-015-1036-7.

78 Georgescu D, Ionita-Radu F, Multescu R, et al. The role of alpha1 blockers in the medical expulsive therapy for ureteral calculi - a prospective controlled randomized study comparing tamusolin and silodosin. Farmacia 2015;63:184-8.

79 Sur RL, Shore N, L'Esperance J, et al. Silodosin to facilitate passage of ureteral stones: a multi-institutional, randomized, double-blinded, placebo-controlled trial. Eur Urol 2015;67:959-64. doi:10.1016/j. eururo.2014.10.049

80 Yuksel M, Yilmaz S, Tokgoz H, et al. Efficacy of silodosin in the treatment of distal ureteral stones 4 to $10 \mathrm{~mm}$ in diameter. Int / Clin Exp Med 2015;8:19086-92.

81 Furyk JS, Chu K, Banks C, et al. Distal ureteric stones and tamsulosin: a double-blind, placebo-controlled, randomized, multicenter trial. Ann Emerg Med 2016;67:86-95.e2. doi:10.1016/i. annemergmed.2015.06.001.

82 Wang C), Tsai PC, Chang CH. Efficacy of silodosin in expulsive therapy for distal ureteral stones: a randomized double-blinded controlled trial. Urol J 2016;13:2666-71.

83 Ueno A, Kawamura T, Ogawa A, Takayasu H. Relation of spontaneous passage of ureteral calculi to size. Urology 1977;10:544-6. doi:101016/0090-4295(77)90097-8.

84 Hübner WA, Irby P, Stoller ML. Natural history and current concepts fo the treatment of small ureteral calculi. Eur Urol 1993;24:172-6.

85 Itoh Y, Kojima Y, Yasui T, Tozawa K, Sasaki S, Kohri K. Examination of alpha 1 adrenoceptor subtypes in the human ureter. Int J Urol 2007;14:749-53. doi:10.1111/j.1442-2042.2007.01812.x.

86 Sigala S, Dellabella M, Milanese G, et al. Evidence for the presence of alpha1 adrenoceptor subtypes in the human ureter. Neurourol Urodyn 2005;24:142-8. doi:10.1002/nau.20097.

87 Park HK, Choi EY, Jeong BC, Kim HH, Kim BK. Localizations and expressions of alpha-1A, alpha-1B and alpha-1D adrenoceptors in human ureter. Urol Res 2007;35:325-9. doi:10.1007/ s00240-007-0118-0

88 Wimpissinger F, Türk C, Kheyfets O, Stackl W. The silence of the stones: asymptomatic ureteral calculi. / Urol 2007:178:1341-4, discussion 1344. doi:10.1016/j.juro.2007.05.128.

Appendix 1: PubMed search strategy

Appendix 2: Supplementary tables A-F

Appendix 3: Supplementary figures 